\title{
Isolation and characterisation of antibodies which specifically recognise the peptide encoded by exon 7 (v2) of the human CD44 gene
}

\author{
A Borgya, A Woodman, M Sugiyama, F Donié, E Kopetzki, Y Matsumura, D Tarin
}

\begin{abstract}
Aims-Exon 7 of the human CD44 gene is overexpressed in many commonly occurring carcinomas. The aim of the study was to explore the diagnostic and therapeutic potential of this frequent abnormality.

Methods-A new monoclonal antibody (mAb, M-23.6.1) and a polyclonal antibody (pAb,S-6127) to the corresponding antigen were raised by immunising mice and sheep, respectively, with a specially constructed fusion protein HIV2 (gp32)-CD44 exon 7.
\end{abstract}

Results-Characterisation of $\mathrm{mAb}$, M-23.6.1 by ELISA, western blotting, immunocytochemistry, and FACS analysis confirmed that it specifically recognises an epitope in the region between amino acids 19 and 33 of the peptide encoded by this exon. Western blotting experiments with two cell lines, RT112 and ZR75-1, known from RT-PCR data to be overtranscribing the exon, yielded a monospecific band of approximately $220 \mathrm{kDa}$, and immunocytochemistry showed discrete membrane staining on the same cell lines. Fluorescent antibody cell sorting (FACS) revealed binding to greater than $90 \%$ of the cells of each of these lines. Specificity of recognition of the antigen was shown by inhibition of the precise immunoreactivity typically seen in ELISA and Western blots, by pre-incubation with synthetic exon 7 peptide or fragments of it.

Conclusions-The new antibodies will be useful tools for the further analysis of abnormal CD44 isoforms and their clinical implications.

(f Clin Pathol: Mol Pathol 1995;48:M241-M250)

Keywords: CD44 antibodies, tumour marker.

There is now much evidence, reviewed below, that the expression of the CD44 gene is severely disturbed in several common types of human cancer. The repertoire of this gene includes a widely distributed family ${ }^{1}$ of highly glycosylated transmembranous glycoproteins showing a di- verse range of functions. The genomic structure of the human CD44 locus shows a 60 kilobase (kb) sequence composed of at least 20 exons. $^{2}$ Nine of these encode the almost ubiquitously expressed "standard" form (exons 1-5 and 1619), while in humans at least a further 10 exons, numbered 7-15 and 20, are subject to inclusion through alternative splicing. This results in a large array of protein isoforms which are differentially expressed in various tissues and at various stages in development.

CD44 was originally described as an antigen on red blood cells and platelets and later work identified it as a lymphocyte homing receptor responsible for facilitating migration through lymph nodes. ${ }^{34}$ However, it is now clear that the various isoforms produced by this gene are involved in a wide variety of cell-cell interactions, which include acting as receptors for hyaluronic acid, ${ }^{56}$ collagen, and fibronectin, ${ }^{78}$ and more recent work has implicated them in tumour development and metastasis..$^{9-13}$ However, the marked increase in the level of activity of the gene in cancer cells and the disorder, including the retention of introns, in the assembly of transcripts ${ }^{14}$ make it difficult to identify which, if any, of the inappropriately expressed elements are the key ones specifically associated with the neoplastic process. Certainly, expression of individual variant exons is altered in several malignancies; for example, that of exon 11 (v6) is increased in colon and breast carcinomas, ${ }^{113}$ of exon 7 in bladder, breast, and colon, ${ }^{15}$ and of exons $12 / 13$ in cervix. ${ }^{16}$ Despite this evidence of grossly disturbed CD44 gene function, there is insufficient information at present to know whether imbalanced expression of an individual exon or of a particular combination of exons is specifically linked with induction and progression of malignancy. While much of this work has relied upon the use of reverse transcription-polymerase chain reaction (RT-PCR) to visualise abnormal gene transcription, several studies investigating CD44 protein expression have reported similar abnormal findings ${ }^{1718}$ in tumours compared with normal tissues.

On the basis of such new observations the notion that abnormalities of CD44 expression could be useful as a diagnostic or prognostic 
marker for malignancy is attracting much clinical interest. As with all new markers, several important issues, such as the availability of appropriate reagents and the reproducibility of the results must be examined and evaluated before they can be introduced into routine practice. Additionally in the case of CD44, which produces many isoforms, the most informative isoforms or component exons must be determined. Currently, it is believed that protein based assays such as enzyme linked immunosorbent assay (ELISA) and immunohistochemistry are the simplest and most flexible for clinical use. Thus the development of specific antibodies to CD44 gene products is vital for the evaluation of the potential role of this protein in routine tumour diagnosis. Various antibodies are available, either commercially or by donation, to the products of several of the standard form exons (for example, F10-44-2, exon 1 (Boehringer Mannheim); Hermes 3, exon 5 (Dr EC Butcher)), as well as to variant exons (for example, $3 \mathrm{G} 5$, exon 8 ( $R$ and D Systems); VFF8, exon 10 (Bender Medisystems); 2F10, exon 11 (R and D Systems); 2G1, exon 15 (Dr DL Cooper)). However, there was until recently no antibody available to the peptide encoded by exon 7 .

Our previous RT-PCR studies had shown that one of the disturbances characteristically seen in many commonly occurring types of carcinoma (for example, breast, colon, and bladder) is the assembly of large transcripts containing the products of all exons, including the recently identified exon $7 .^{115}$ The formulation of methods for simple rapid detection of large CD44 protein isoforms containing a segment encoded by this exon was therefore identified as an important priority. To satisfy this need, we constructed a fusion protein (HIV2gp32-CD44 exon 7) which was successfully used to raise monoclonal and polyclonal antibodies specifically recognising this component of human CD44, as described below.

\section{Methods \\ PREPARATION OF SYNTHETIC PEPTIDES AND FUSION PROTEINS FOR CD44 EXON 7 \\ Peptide synthesis}

The sequence of CD44 exon 7 was obtained from Matsumura et al. ${ }^{15}$ Synthetic peptides corresponding to amino acids $1-43,1-13,9$ $23,19-33$, and $29-43$ encoded by this sequence were synthesised to use in screening mono- clonal antibodies against fusion proteins (see below). This was accomplished by 9-fluoronylmethyloxycarbonyl (Fmoc) chemistry solid phase peptide synthesis on an Applied Biosystems model $431 \mathrm{~A}$ peptide synthesizer, using the $0.25 \mathrm{mmol}$ scale. Briefly, a 4 molar excess of amino acid derivatives was dissolved in dimethylformamide (DMF) and activated by the addition of $N$-hydroxybenzotriazole ( $\mathrm{HOBt}$ ) in $N$-methylpyrrolidinone (NMP) and $N, N^{\prime}$-dicyclocarbodiimide (DCC) in NMP. Twenty minute couplings in DMF were followed by deprotection of the $N$-termini by 3 and $10 \mathrm{~min}$ treatments with $20 \%$ piperidine in DMF. The peptide chain was extended through repetition of the activation/coupling/deprotection cycles. The $N$-terminus contained three $\gamma$-aminobutyric acid moieties, lysine, and biotin (attached to $\varepsilon$-amino group of lysine). The peptides were removed from the resin using trifluoroacetic acid (TFA) and scavengers. They were then precipitated in di-isopropylether, filtered, washed in di-isopropylether dissolved in $50 \%$ acetic acid, and freeze dried. Peptide purity was determined by reverse phase HPLC and identity verified by plasma desorption mass spectrometry. The sequences of the five synthetic peptides are shown in fig 1 .

\section{Fusion protein synthesis}

For immunisation, biologically synthesised exon 7 proteins were used in an attempt to produce an antigen corresponding as closely as possible to the natural configuration in cells. As CD44 exon 7 encodes a peptide of only 43 amino acids, it is not suitable for cytoplasmic expression in a micro-organism. Therefore a duplicated fusion gene expressible in $E$ coli, comprising of a part of the envelope protein gp32 of the HIV2 retrovirus ligated to two copies of the CD44 exon 7-DNA sequence in head to tail tandem repeat orientation, was constructed.

Construction of HIV2 (gp32)-partial gene (plasmid pUC18-HIV2-gp32) and $\mathrm{E}$ coli expression vector $p D S 56-6 H I S-H I V 2-g p 32$

The coding section of amino acids 48-162 of the HIV2-gp32 gene ${ }^{19}$ was synthesised by overlapping chemical gene synthesis and subsequent subcloning in the pUC18 plasmid. Then a fusion gene was constructed which codes for the $N$-terminus of the amino acid sequence MRGSHHHHHHTDPEF (poly-

CD44 exon 7 (1-13aa)-TLJSTSATATETA- $\mathrm{NH}_{2}$

CD44 exon 7 (9-23aa)-ATETATKRQETWDWF-NH ${ }_{2}$

CD44 exon 7 (19-33aa)-TWDWFSWLFLPSESK- $\mathrm{NH}_{2}$

CD44 exon 7 (29-43aa)-PSESKNHLHTTTQJA-NH ${ }_{2}$

CD44 exon 7 (1-43aa) TLJSTSATATETAKRQETWDWFSWLFLPSESKNHLHTTTQJA-NH ${ }_{2}$ 
His tail) and the selected HIV2-gp32 antigen. For this, the vector pQE-10 (Viagen, Germany) ${ }^{20}$ was digested with the restriction endonucleases BamHI and HindIII, and the resultant $3.4 \mathrm{kbp}$ vector fragment isolated by agarose gel electrophoresis. Subsequently, the plasmid pUC18-HIV2-gp32 was digested by the restriction endonucleases BamHI and HindIII, and the $400 \mathrm{bp}$ fragment isolated and ligated into the $3.4 \mathrm{kbp} \mathrm{BamHI} / \mathrm{HindIII}-\mathrm{pQE}$ 10 vector fragment. The desired plasmid was identified by restriction mapping and designated pDS56-6HIS-HIV2-gp32.

Construction of $\mathrm{E}$ coli expression vector pDS56HIV2-CD44 exon 7

A fusion gene was constructed which encodes the $N$-terminus for the amino acid sequence MRGSHHHHHHTDPEF (poly-His tail), the selected HIV2-gp32 antigen and two copies of the CD44 exon 7 antigen. Two CD44 exon 7 gene fragments were produced by two polymerase chain reactions (PCR). ${ }^{21}$ In the first PCR, CD44 exon 7 DNA sequence was amplified from a template of subcloned CD44 cDNA (exon 5 to 11) incorporating the singular restriction endonuclease cleavage sites BamHI and HaeIII at the $5^{\prime}$ and $3^{\prime}$ end respectively. The PCR product was digested with Bam HI and HaeIII and the $150 \mathrm{bp} \mathrm{BamHI/HaeIII-}$ CD44 exon 7 fragment purified by agarose gel electrophoresis. In the second PCR, the CD44 exon 7 DNA sequence was amplified from subcloned CD44 (exon 5 to 11) as template and provided with the singular restriction endonuclease cleavage sites HaeIII and HindIII at the $3^{\prime}$ and $5^{\prime}$ end respectively. After digestion with HaeIII and HindIII the $140 \mathrm{bp}$ BamHI/ HaeIII-CD44 exon 7 fragment was isolated by agarose gel electrophoresis.

The BamHI/HaeIII-CD44 exon 7 fragment from the first PCR reaction and the HaeIII/ HindIII-CD44 exon 7 from the second PCR reaction were ligated by three-fragment ligation into the $3.8 \mathrm{kbp} \mathrm{BgI} \mathrm{II/HindIII-pDS56-6HIS-}$ HIV2-gp32 vector fragment. The plasmid was identified by restriction mapping and the PCR synthesised DNA regions checked by DNA sequencing.

Expression of HIV2(gp32)-CD44 exon 7 antigen in $\mathrm{E}$ coli

The $E$ coli $\mathrm{K} 12$ strain RM82 (a methionine revertant of ED8654 ${ }^{22}$ ) was transformed with the expression plasmid pDS56-HIV2-CD44 exon 7 (ampicillin resistance) described above and the IacI repressor plasmid pUHAl (kanamycin resistance).$^{20}$ The transformed cells were cultured in DYT medium ( $1 \%$ ( $w t / v o l)$ yeast extract, $1 \%$ (wt/vol) Bacto Tryptone, Difco, and $0.5 \% \mathrm{NaCl}$ ) ampicillin and kanamycin $(50 \mathrm{mg} / \mathrm{l})$ up to an absorbance of $0.6-0.9$ at $550 \mathrm{~nm}$. Cells were then induced with IPTG $(1-5 \mathrm{mmol} / \mathrm{l})$ for $4-8 \mathrm{~h}$. The cells were harvested, washed with $10 \mathrm{mmol} / 1$ phosphate buffer ( $\mathrm{pH} 6.8$ ) and stored at $-20^{\circ} \mathrm{C}$ until required.
Preparation of HIV2(gp32)-CD44 exon 7 antigen from $\mathrm{E}$ coli

To extract the expressed proteins from the cells, $20 \mathrm{~g}$ (wet weight) of RM82/pUHA1/pDS56HIV2-CD44 exon 7 cells were resuspected in $100 \mathrm{ml} 0 \cdot 1 \mathrm{M}$ Tris- $\mathrm{HCl}, \mathrm{pH} 7$, at $0^{\circ} \mathrm{C} ; 30 \mathrm{mg}$ lysozyme were added and the mixture was incubated for $20 \mathrm{~min}$ at $0^{\circ} \mathrm{C}$, before the cells were lysed completely by mechanical dispersion (French press) and the DNA digested by the addition of $2 \mathrm{mmol} / 1 \mathrm{MgCl}_{2}$ and $1 \mathrm{mg}$ DNAase at $25^{\circ} \mathrm{C}$ for $30 \mathrm{~min}$. Then $50 \mathrm{ml}$ of $60 \mathrm{mmol} / 1$ EDTA, $6 \%$ Triton X100, and $1.5 \mathrm{M} \mathrm{NaCl}, \mathrm{pH}$ $7 \cdot 0$, were added to the digestion mixture and incubated for a further $30 \mathrm{~min}$ at $0^{\circ} \mathrm{C}$. The insoluble components (cell debris and inclusion bodies) were pelleted, resuspended in $100 \mathrm{ml}$ phosphate buffer $(0.1 \mathrm{M} ; \mathrm{pH} 8.5)$, and incubated for $30 \mathrm{~min}$ at $25^{\circ} \mathrm{C}$ before the inclusion body products were isolated by centrifugation.

Purification of HIV2 (gp32)-CD44 exon 7 antigen using metal chelate affinity chromatography The ability of accessible neighbouring histidine residues (poly-His tail) to form tightly associated complexes with immobilised/chelated nickel ions was used for affinity purification of the HIV2(gp32)-CD44 exon 7 protein. Affinity purification of the HIV2(gp32)-CD44 exon 7 antigen was according to the method reviewed by Stueber et al..$^{20}$ Briefly, the inclusion body pellet $(2.5 \mathrm{~g}$ wet weight) was suspended in $25 \mathrm{ml} 6 \mathrm{M}$ guanidine- $\mathrm{HCl}, 0 \cdot 1 \mathrm{M}$ phosphate buffer, $\mathrm{pH} 8.5$, and stirred for $2 \mathrm{~h}$ at $25^{\circ} \mathrm{C}$. The insoluble components were separated by centrifugation and the clear supernatant applied to an Ni-NTA-agarose resin column (ligand: NTA, nitrilotriacetic acid ${ }^{23}$ ) equilibrated with $6 \mathrm{M}$ guanidine- $\mathrm{HCl}, 0 \cdot 1 \mathrm{M}$ phosphate buffer, pH 8.5 (column volume: $50 \mathrm{ml}$, NiNTA agarose from Diagen). The column was washed with five volumes of $8 \mathrm{M}$ urea, $10 \mathrm{mmol} / 1$ Tris-HCL, and $0.1 \mathrm{mmol} / 1$ phosphate buffer $\mathrm{pH} 8 \cdot 5$. The HIV2(gp32)-CD44 exon 7 antigen which had been bound to the nickel by the poly-His tail, was eluted with $8 \mathrm{M}$ urea, $0 \cdot 1 \mathrm{M}$ phosphate buffer, $\mathrm{pH} 4 \cdot 0$. The full amino acid sequence of the resultant HIV2(gp32)-CD44 exon 7 fusion protein is shown in fig 2 .

PREPARATION AND CHARACTERISATION OF MURINE MONOCLONAL ANTI-CD44 EXON 7 ANTIBODIES

Pathogen-free Balb/c mice, approx 12 weeks old, were primed by intraperitoneal (ip) injection of $100 \mu \mathrm{g}$ of purified CD44 exon 7 fusion protein (HIV2(gp32)-CD44 exon 7) in Freund's complete adjuvant. The immune response was boosted by reinjecting a similar dose of antigen in Freund's incomplete adjuvant every four weeks for 12 weeks. A final course of injections of $100 \mu \mathrm{g}$ antigen/mouse in phosphate buffered saline (PBS) was given intravenously (iv) 72,48 , and $24 \mathrm{~h}$ before their spleen cells were harvested for fusion with myeloma cells to generate hybridomas.

Splenocytes were harvested from immunised 


\section{MRGSHHHHHHTDPEF QQQQQLLDVVKRQQELLRLTVWGTKNLQARVTAIE (poly-HIS)}

\section{KYLQDQARLNSWGCAPRQVCHTTVPWVNDS LAPDWDNMTWQEWEKQ HIV2 (gp32)-117aa}
VRYLEANISKSLEQAQ1QQEKNMYELQKLNSWD IRS PAT TLMST
Exon $5 ; 3$ aa

\section{SATATETATKROETWDWFSWLFLPSESKNHLHTTTOMA PAT TLMSTSA Exon 7 ;43aa Exon 5;3aa}

\section{TATETATKROETWDWFSWLFLPSESKNHLHTTTOMA}

$$
\text { Exon 7;43aa }
$$

One letter code; $a \mathrm{a}=$ amino acid. Bold capitals $=117$ aa section of HIV2(gp32). Bold capitals italic $=3$ aa section of CD44 exon 5 . Bold capitals underlined $=43$ aa of full CD44 exon 7.

Figure 2 Protein sequence of HIV2 (gp32)-CD44 exon 7 fusion protein.

mice and fused with mouse myeloma cells according to Kohler and Milstein. ${ }^{24}$ Briefly, splenocytes harvested by physical disruption were mixed in a 5:1 ratio with $\mathrm{P} 3 \times 63 \mathrm{Ag} 8-653$ mouse myeloma cells. Fusion was induced by incubation of the cell pellet with $50 \%$ polyethylene glycol 1500 (Boehringer Mannheim) for $1 \mathrm{~min}$ at $37^{\circ} \mathrm{C}$. The fused cells were plated out in flat bottomed 96-well plates (Nunc) at $2 \times 10^{4}$ cells per well in RPMI 1640 containing $10 \%$ fetal calf serum (FCS), azaserine-hypoxanthine (Sigma), and $100 \mathrm{U} / \mathrm{ml}$ interleukin-6 (Boehringer Mannheim) as a cytokine to replace feeder cells.

Supernatants were taken for screening at day 10 from wells with more than $30 \%$ confluent hybridoma cells. Reactivity was determined against the CD44 exon 7 fusion protein and against the CD44 exon 7 (1-43aa) peptide by an ELISA (see below). The positive hybridomas were further selected by testing their reactivity to natural CD44 exon 7 on cell lines in a cell ELISA (see below) and in western blotting. Further cloning of cells producing antibodies which specifically bind to natural CD44 exon 7 was undertaken using a fluorescent antibody cell sorter (FACS; Becton Dickinson). Supernatants of growing monoclonal antibodies were tested in the same way at the primary supernatants.

Reactive epitopes were mapped by preincubation of supernatants with $5 \mu \mathrm{g} / \mathrm{ml}$ of the five synthetic peptides (described above) (143aa, 1-13aa, 9-23aa, 19-33aa, 29-43aa) for $1 \mathrm{~h}$ at $37^{\circ} \mathrm{C}$. Immunoreactivity was then determined in the peptide ELISA.

Three CD44 exon 7 specific hybridomas were selected for bulk production and purification. The class of these antibodies was determined by an iso-strip antibody isotyping kit (Boehringer Mannheim). Bulk production was undertaken by two methods: in vitro spinner flask culture (inoculum of $1 \times 10^{5}$ cells $/ \mathrm{ml}$ in RPMI $1640+10 \%$ FCS; stirred at $37^{\circ} \mathrm{C}$ for $7 \mathrm{~d}$ on a Techne biological stirrer) or in vivo in athymic nude mice, primed with pristane (Sigma) $10 \mathrm{~d}$ before an ip injection of $0.5 \times 10^{6}$ hybridoma cells/mouse; ascites was harvested after 7-14 d. The resultant IgG obtained by both methods was purified by absorption to protein A (using Bio-Rad MAPS II kit).

The purified mouse IgG samples thus obtained were characterised by ELISA, FACS scan, western blotting, and immunocytochemistry as follows.

ELISA for CD44 exon 7 fusion protein and synthetic peptide

For the fusion protein ELISA, 96-well microtitre plates were coated with $5 \mu \mathrm{g} / \mathrm{ml}$ fusion protein HIV2(gp32)-CD44 (exon 7) in carbonate coating buffer (Boehringer Mannheim) for $1 \mathrm{~h}$ at room temperature. Free binding sites were blocked for 30 min with blocking buffer containing $1 \%$ crotein $\mathrm{C}$.

For the synthetic peptide ELISA, 96-well microtitre plates were coated with $200 \mu \mathrm{l} /$ well streptavidin. After blocking with $1 \%$ crotein C, $2.5 \mu \mathrm{g} / \mathrm{ml}$ biotinylated peptide CD44 exon 7 (1-43aa) were bound to the plate in incubation buffer (sodium phosphate $40 \mathrm{mM}, 0.5 \%$ crotein $\mathrm{C}$ ) for $1 \mathrm{~h}$ at room temperature. After coating, both ELISAs were treated as follows.

The culture supernatants to be tested were added with or without the free peptides described above (1-43aa)(1-13aa)(9-23aa) (1933) and (29-43) at $5 \mu \mathrm{g} / \mathrm{ml}$ and incubated for $1 \mathrm{~h}$ at room temperature. Wells were washed again before the addition of $20 \mathrm{mU} / \mathrm{ml}$ peroxidase labelled sheep anti-mouse $F c$-gamma and $F a b$ fragments (Boehringer Mannheim) and incubation for $1 \mathrm{~h}$ at room temperature. Reactivity was determined by incubating the wells with the colour substrate ABTS (Boehringer Mannheim) for $30 \mathrm{~min}$ at room temperature. The absorbance at $450 / 490 \mathrm{~nm}$ was measured on a Dynatech MR 700 microplate reader. Wells were washed with PBS containing $0.05 \%$ Tween 20 between each incubation step.

\section{Cell ELISA for CD44 exon 7}

For the screening by cell ELISA two cell lines were used: RT112, a human bladder carcinoma 
line (ECACC No. 85061106) showing high exon 7 expression as determined by RT-PCR; and MDA-4A4, a subclone from MDA-MB435 (donated by Dr Janet Price), a human breast carcinoma line, with no detectable exon 7 transcription.

The cells were grown in 96-well plates in Dulbecco's modified Eagle's medium (DMEM) $+10 \%$ FCS until $70-80 \%$ confluent. The culture medium was removed, cells washed with PBS, and allowed to air dry. Cells were fixed with cold methanol and stored at $-20^{\circ} \mathrm{C}$. Before use, plates were given $15 \mathrm{~min}$ to return to room temperature and non-specific sites were blocked with blocking buffer containing $1 \%$ crotein $\mathrm{C}$. Test supernatants/antibodies were incubated either for $2-4 \mathrm{~h}$ at room temperature or overnight at $4^{\circ} \mathrm{C}$. Wells were then incubated with $20 \mathrm{mU} / \mathrm{ml}$ peroxidase labelled sheep anti-mouse $F a b$ fragments (Boehringer Mannheim) for $1 \mathrm{~h}$ at room temperature. Reactivity was determined by the addition of the colour substrate BM-Blue (Boehringer Mannheim), and incubated for 30 min at room temperature before the reaction was stopped with $1 \mathrm{M} \mathrm{H}_{2} \mathrm{SO}_{4}$. The absorbance was measured at $450 / 690 \mathrm{~nm}$ in an SLT 340 ATTC microplate reader. Wells were washed between each step with PBS containing 0.1\% Tween 20 .

\section{Western blotting}

RT112, MDA 4A4, HT29 (human colon carcinoma), and ZR75 (human breast carcinoma; ATCC No CRL 1500) cell lines were grown to $70-80 \%$ confluence in DMEM $+10 \%$ FBS. The cells were removed from the flask using a flexible cell scrapper (Gibco) and washed in PBS $+0.02 \mathrm{mmol} / 1$ amidinophenylmethane sulphonyl fluoride (APMSF) (Sigma) and $1 \mathrm{mmol} / 1 \mathrm{EDTA}$ as protease inhibitors. The cell pellet collected by centrifugation at $600 \mathrm{~g}$ for $15 \mathrm{~min}$ was lysed on ice for $15 \mathrm{~min}$ with $1: 1$ lysis buffer (composition in mmol/l: tris 20 (pH 8), $\mathrm{NaCl} 150$, CHAPS 20, EDTA 2, APMSF $0 \cdot 04$, plus $20 \mu \mathrm{g} / \mathrm{ml}$ aprotinin). The resultant lysate was clarified by centrifugation (10000 $g, 15 \mathrm{~min}$ ), protein concentration determined (Bio-Rad protein assay kit), adjusted to $1 \mathrm{mg} /$ $\mathrm{ml}$ by dilution with PBS, and mixed 1:1 (vol/ vol) with gel loading buffer. Lysates and molecular weight standards were boiled for $5 \mathrm{~min}$ before separation by $6 \%$ SDS-PAGE under reduced conditions. The separated proteins were electroblotted $(100 \mathrm{~mA}, 1 \mathrm{~h})$ to immobilon-P membrane (Millipore) using transfer buffer $48 \mathrm{mmol} / 1$ tris, $39 \mathrm{mmol} / 1$ glycine, $0 \cdot 1 \%$ SDS, $20 \%$ methanol, $\mathrm{pH} 9 \cdot 2$ ). Nonspecific reactions were blocked with tris buffered saline (TBS) containing 5\% skimmed milk before the membrane was incubated overnight at $4^{\circ} \mathrm{C}$ with either mAb Hermes-3 (antistandard CD44 exon 5) $(1 / 1000)$ as a positive control or test supernatants/antibodies. Reactivity was determined by the addition of peroxidase conjugated anti-mouse IgG (Sigma or Boehringer Mannheim, 1/1000) for $1 \mathrm{~h}$ at room temperature and the signals visualised using the enhanced chemiluminescence (ECL) detection system (Amersham or Boehringer Mannheim). Hermes-3, ascites, and purified antibodies were diluted in $5 \%$ skimmed milk, the membrane was washed between each incubation step with TBS containing $0 \cdot 1 \%$ Tween 20 .

\section{Immunocytochemistry}

To determine the cellular localisation of the epitopes recognised by the test antibodies, the RT112, ZR75, MDA 4A4, and HT29 cell lines were grown to $75 \%$ confluence on slide flasks (Gibco) in DMEM containing 10\% FBS. These cell lines were chosen for use in screening the antibodies because RT112 and ZR75-1 had been shown in earlier RT-PCR studies to show high levels of CD44 exon 7 transcription, while in HT29 and MDA 4A4 this activity was undetectable. It had to be assumed, for the purposes of this work, that the mRNA levels reflected the content of the corresponding protein in these cell lines, which later proved to be correct.

The base of each flask was removed and the adherent cells washed three times with PBS before fixation in cold methanol $\left(10 \mathrm{~min}, 4^{\circ} \mathrm{C}\right)$. Non-specific reactions were blocked by preincubation with $20 \%$ normal rabbit serum diluted in TBS at $37^{\circ} \mathrm{C}$ for $45 \mathrm{~min}$ before incubation with Hermes-3 (1/50) or test supernatants/antibodies overnight at $4^{\circ} \mathrm{C}$. Any endogenous peroxidase activity was blocked with 3\% hydrogen peroxide in methanol for 10 min before the addition of biotinylated antimouse IgG (Dako, 1/400 dilution, room temperature, $2 \mathrm{~h}$ ) and horseradish peroxidase conjugated ABComplex (Dako, room temperature, $1 \mathrm{~h}$ ). Immunostaining was visualised using diaminobenzidine $/ \mathrm{H}_{2} \mathrm{O}_{2}$ (Sigma) as substrate; cells were counterstained with haematoxylin. Between all antibody incubations, cells were washed by $3 \times 5 \mathrm{~min}$ incubations with TBS on a shaking platform.

\section{Immunofluorescent staining and flow cytometry}

For one colour immunofluorescence staining, RT112/84, MDA 4A4, ZR 75-1 cell lines or unstimulated peripheral blood lymphocytes $\left(5 \times 10^{5}\right.$ cells) were incubated with hybridoma supernatant containing $10 \mu \mathrm{g} / \mathrm{ml}$ of $\mathrm{mAb}(30$ $\left.\min , 4^{\circ} \mathrm{C}\right)$. Cells were washed once and resuspended in $100 \mu \mathrm{l}$ of FITC labelled sheep anti-mouse Ig $\mathrm{F}(\mathrm{ab})_{2}$ fragment (Boehringer Mannheim) for $30 \mathrm{~min}$ at $4^{\circ} \mathrm{C}$. Subsequently, they were washed and resuspended in phosphate buffer $(100 \mu \mathrm{l})$ before fixing in $1 \mathrm{ml}$ of methanol $(0.5 \%)$ and storage at $4^{\circ} \mathrm{C}$. Before FACS analysis, the cells were washed again and resuspended in $250 \mu \mathrm{l}$ phosphate buffer. FACS analysis was carried out in accordance with manufacturer's instructions.

\section{Determination of immunoglobulin class and light chain}

The mouse monoclonal antibody isotyping kit (Iso-Strip; Boehringer) was used. Culture supernatants $(150 \mu \mathrm{l})$ diluted 1:100 (v/v) in PBS 
Table 1 Reactivity of primary hybridoma supermatants with different CD44 v2 peptide regions shown by inhibition assay using specific synthetic peptides. Figures denote absorbance values at $450 \mathrm{~nm}$

\begin{tabular}{llllll}
\hline Primary culture & Without peptide & $v 2(1-43)$ peptide & $v 2(1-13)$ peptide & v2 (9-23) peptide & v2 (19-33) peptide \\
\hline 23.000 .1 & 1.941 & 0.066 & 1.467 & 0.595 & 0.595 \\
23.000 .5 & 0.763 & 0.046 & 0.547 & 0.729 & 0.052 \\
23.000 .6 & 1.022 & 0.067 & 0.825 & 0.785 & 0.057 \\
23.000 .8 & 0.576 & 0.050 & 0.499 & 0.503 & 0.056 \\
23.000 .9 & 0.400 & 0.058 & 0.334 & 0.382 & 0.066 \\
23.000 .10 & 0.505 & 0.142 & 0.187 & 0.620 & 0.497 \\
23.000 .19 & 1.247 & 0.060 & 1.184 & 1.306 & 0.094 \\
23.000 .20 & 0.828 & 0.058 & 0.696 & 0.840 & 0.062 \\
\hline
\end{tabular}

were added to the development tube and incubated at room temperature for $30 \mathrm{~s}$. The tubes were agitated by a brief vortex to resuspend the coloured latex before insertion of the iso-typing strip. The results were interpreted after $5 \mathrm{~min}$ by the appearance of a blue band in either the $\kappa$ or $\lambda$ section of the strip and in one of the class or subclass sections. The positive control bands on either side of the isotype strip must also appear indicating that the antibody coated latex beads were functional and had attached to the strip.

\section{PREPARATION OF SHEEP ANTI-CD44 EXON 7} POLYCLONAL ANTIBODIES

To allow applications to be undertaken where polyvalent antibodies may be advantageous, sheep (Merino Suffolk) were immunised and boosted with $100 \mu \mathrm{g}$ HIV2(gp32)-CD44 (exon 7) fusion protein in Freund's adjuvant. After 12 weeks, animals were test bled and the serum screened for immunoreactivity in the CD44 exon 7 peptide ELISA and cell ELISAS.

\section{Purification}

Ammonium sulphate was added to the serum to a final concentration of $1.7 \mathrm{M}$. After dialysis the precipitate was applied to a DEAEsepharose column (Pharmacia) and eluted by increasing the $\mathrm{NaCl}$ concentration. The CD44 exon specific IgG within the total IgG was prepared by immunosorption. CD44 exon 7 (1-43aa) peptide synthesised with an additional spacer and cystein at the amino terminus was coupled to aminospherosil (Boehringer Mannheim) activated by maleimidohexanol- $N$ hydroxysuccinimide. The IgG fraction of the DEAE column was applied to the CD44 exon 7 column in PBS at $\mathrm{pH} 7 \cdot 4$. The bound CD44 exon 7 specific IgG fraction was then eluted by $3 \mathrm{mmol} / 1 \mathrm{HCl}$. Approximately $5 \%$ of the total IgG were specific to CD44 exon 7. Purified IgG was further characterised by western blotting and immunocytochemistry on RT112, MDA 4A4, and HT29 cell lines.

\section{Results}

SCREENING OF PRIMARY CULTURES

Ten mice immunised with the CD44 exon 7 fusion protein showed positive antibody titres (1:1000-1:2000) against the fusion protein and exon 7 synthetic peptides (1-43aa), (1-13aa), and (19-33aa) (data not shown).

To date, five cell fusion experiments have been performed, each with cells from the spleen of a separate immunised mouse. The supernatants of all resulting clones were screened by ELISA for reactivity against CD44 exon 7 peptide (1-43) and natural CD44 exon 7 encoded epitopes on the RT112 cell line between 10-14 d postfusion. One fusion was more promising than the others and from this 480 clones yielded nine positive wells in the peptide ELISA (1-43aa) (table 1). Furthermore the immunoreactivities of seven of these nine primary cultures were inhibited with free (19-33aa) peptide and the remaining two showed inhibition with free peptide (1-13aa) (table 1). In cell ELISA, six of the nine primary cultures gave significant immunoreactivity against RT112, and none of them, as expected, showed reactivity to MDA 4A4 (negative control). RPMI 1640 was used as the background control and the monoclonal antibody F10-44-2 (anti-standard CD44 exon 1) was included as a positive control (table 2 ).

\section{SCREENING AND EPITOPE MAPPING OF} SUBCLONED CULTURES

The six primary hybridoma cultures producing antibodies reacting with CD44 exon 7 peptide

Table 2 Reactivity of CD44 v2 primary hybridoma culture supernatants with natural $C D-44$ v2 on cell lines shown by (cell ELISA). The values represent absorbance at $405 \mathrm{~nm}$

\begin{tabular}{lll}
\hline Primary culture & RT112 cells & MDA 4 A4 cells \\
\hline $23.000 \cdot 1$ & $0 \cdot 850$ & $0 \cdot 237$ \\
23.000 .2 & $0 \cdot 733$ & $0 \cdot 243$ \\
23.000 .6 & 0.830 & $0 \cdot 262$ \\
23.000 .10 & 0.348 & $0 \cdot 250$ \\
23.000 .19 & 0.689 & $0 \cdot 252$ \\
23.000 .20 & $1 \cdot 010$ & $0 \cdot 254$ \\
RPMI-1640 & $0 \cdot 210$ & $0 \cdot 273$ \\
MAK $<$ CD44std $>$ F10 & $1 \cdot 536$ & $1 \cdot 357$
\end{tabular}

Table 3 Reactivity of cloned hybridoma supernatants with natural CD44v2 on cell lines shown by (cell ELISA). Figures denote absorbance at $405 \mathrm{~nm}$

\begin{tabular}{lll}
\hline Clone & RT112 cells & MDA 4 A4 cells \\
\hline 23.6 .1 & $0 \cdot 892$ & $0 \cdot 263$ \\
23.9 .1 & $0 \cdot 878$ & $0 \cdot 265$ \\
23.10 .1 & $0 \cdot 900$ & $0 \cdot 275$ \\
23.11 .2 & $0 \cdot 684$ & $0 \cdot 263$ \\
23.12 .2 & $0 \cdot 929$ & $0 \cdot 286$ \\
23.22 .6 & $0 \cdot 884$ & $0 \cdot 217$ \\
23.26 .6 & $0 \cdot 896$ & $0 \cdot 212$ \\
23.32 .10 & $0 \cdot 372$ & $0 \cdot 255$ \\
23.34 .10 & $0 \cdot 388$ & $0 \cdot 286$ \\
23.45 .19 & $0 \cdot 748$ & $0 \cdot 252$ \\
23.46 .19 & $0 \cdot 749$ & $0 \cdot 274$ \\
23.48 .19 & $0 \cdot 685$ & $0 \cdot 242$ \\
23.51 .20 & $1 \cdot 064$ & $0 \cdot 276$ \\
23.57 .20 & 0.999 & $0 \cdot 297$ \\
RPMI-1640 & $0 \cdot 210$ & $0 \cdot 273$ \\
MAK<CD-44std>F10 & 1.536 & 1.357 \\
\hline
\end{tabular}


Table 4 Reactivity of the monoclonal antibody with different CD 44 v2 peptides, epitope mapping (inhibition test with free peptides)

\begin{tabular}{|c|c|c|c|c|c|}
\hline Clone & $v 2(1-43 a a)$ & $v 2(1-13 a a)$ & $v 2(9-23 a a)$ & $v 2(19-33 a a)$ & $v 2(29-43 a a)$ \\
\hline 23.6 .1 & + & - & - & + & - \\
\hline 23.9.1 & + & - & - & + & - \\
\hline 23.11 .2 & + & + & - & - & - \\
\hline 23.12 .2 & + & + & - & - & - \\
\hline 23.22 .6 & + & - & - & + & - \\
\hline 23.26 .6 & + & - & - & + & _ \\
\hline 23.32 .10 & + & + & - & - & - \\
\hline 23.34 .10 & + & + & - & - & - \\
\hline 23.45 .19 & + & - & - & + & - \\
\hline 23.46 .19 & + & - & - & + & - \\
\hline 23.48 .19 & + & - & - & + & - \\
\hline 23.51 .20 & + & - & - & + & - \\
\hline 23.57 .20 & + & - & - & + & - \\
\hline $\mathrm{MAK}<\mathrm{CD}-44 \mathrm{std}>\mathrm{F} 10$ & - & - & - & - & - \\
\hline
\end{tabular}

+ , positive inhibition with the free peptide $>70 \% ;-$, no inhibition with free peptide $<10 \%$.

(1-43aa) and native CD44 were subcloned and supernatants from 14 of the resulting hybridoma cell line were, as shown in table 3, found to show immunoreactivity to RT 112 but not to MDA 4A4. The anti-CD44 standard form $\mathrm{mAb} F 10-44-2$ showed strong reactivity with MDA 4A4 cells, confirming that they produce mainly this isoform of the CD44 protein.

The reactive epitopes of the six hybridoma lines were mapped by an inhibition assay with overlapping CD44 exon 7 sequences in the peptide ELISA. Table 4 summarises the results. The reactivity of all supernatants was inhibited by the free peptide CD44 exon 7 (1-43aa). As the data shows, this inhibiton was in all cases due to antibodies binding to epitopes either in the (1-13aa) or (19-33aa) regions of CD44
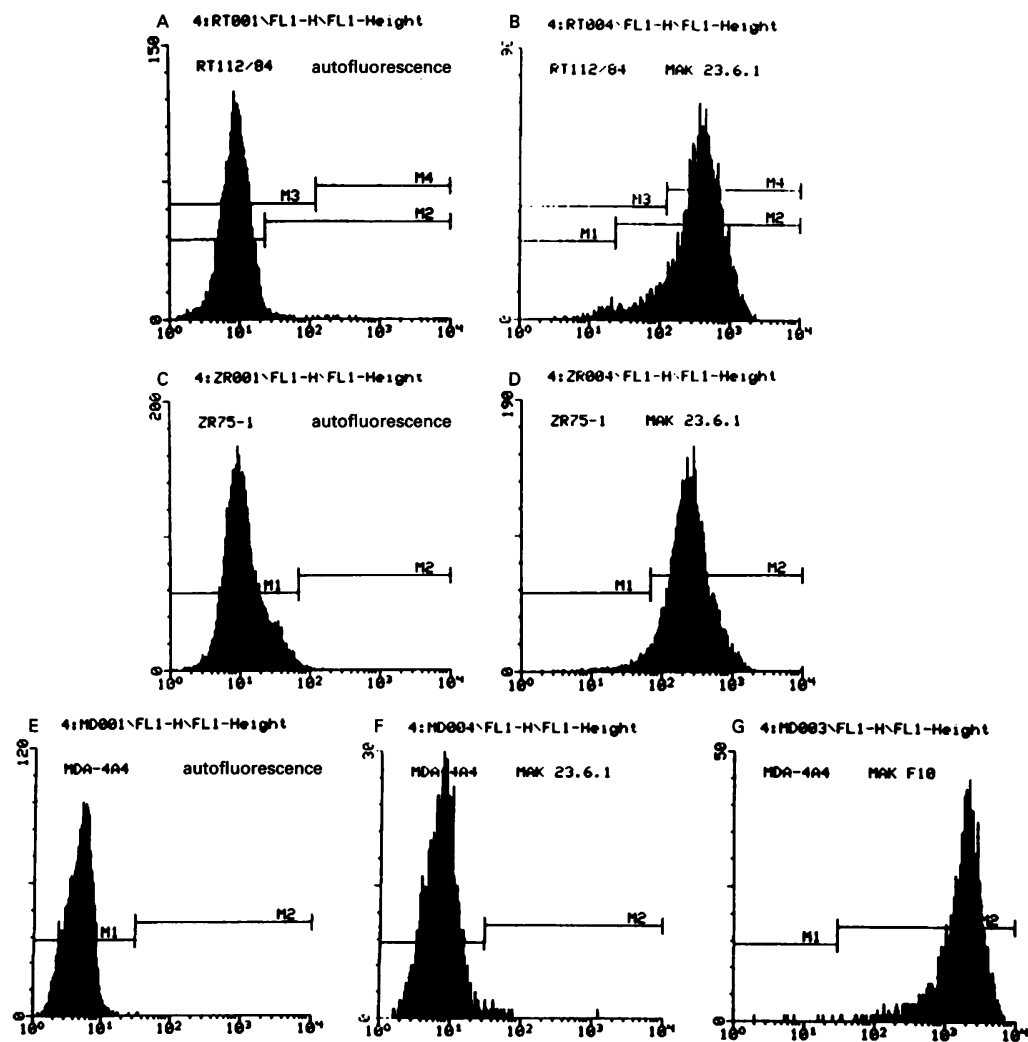

Figure 3 FACScan analysis of cell lines stained with $m A b$ M23.6.1 specific for $C D 44$ exon 7 (v2) and $m A B$ F1044-2 for the CD44 standard form (Boehringer Mannheim, Cat No 1441. 272). (A) RT112 cells: autofluorescence of the cells: 0.09\%; (B) RT112 cells: binding with mAb 23.6.1: 90\%; (C) ZR-75-1 cells: autofluorescence of the cells: 0.28\%; (D) ZR-75-1 cells: binding with mAb 23.6.1: 97\%; (E) $M D A 4 A 4$ cells: autofluorescence of the cells: $0.02 \%$; (F) $M D A 4 A 4$ cells: binding with mAb M23.6.1: $1 \%$; (G) MDA $4 A 4$ cells: binding with $m A b$ F1044-2: $100 \%$ exon 7. No immunoreactivity was observed in the (9-23aa) or (29-43aa) regions. As expected, the F10-44-2 monoclonal antibody to the epitope encoded by standard CD44 exon 1 was not inhibited by any of the peptides.

WESTERN BLOT AND IMMUNOCYTOCHEMICAL ANALYSIS OF PRIMARY AND SUBCLONED CULTURES

Supernatants from the 14 subclones shown to be positive in the peptide and cell ELISAS were further characterised in western blot analysis of RT112 and ZR75 cell lysates under reduced conditions. Positivity in western blot preparations was defined as the presence of a monospecific band with a molecular weight greater than $200 \mathrm{kDa}$ in lysates from both of these cell lines. All were confirmed to show such positivity in varying degree.

Additionally the subclones were characterised by their ability to detect CD44 exon 7 immunocytochemically on these cell lines. Not surprisingly, as these subclones had been found to be positive in cell ELISA, all 14 showed some degree of discrete membrane staining, but

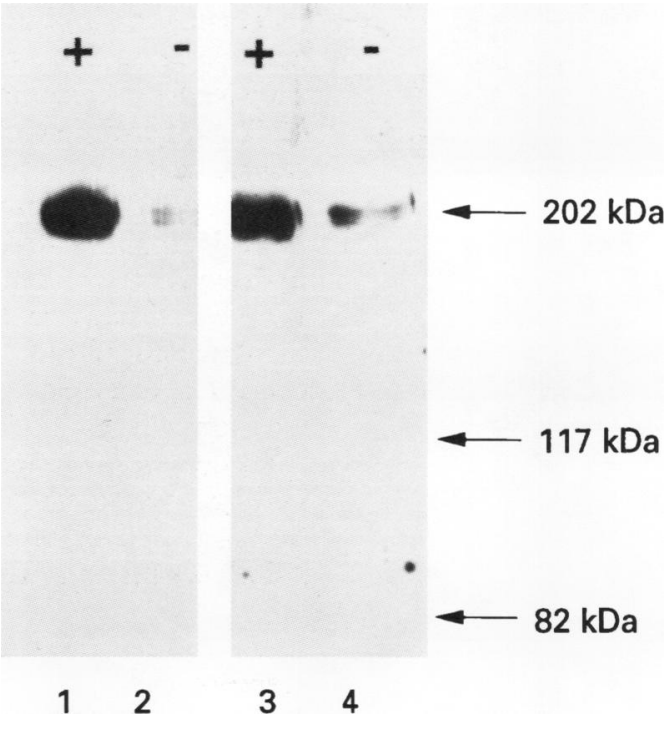

Figure 4 Western blot of RT112 (human bladder carcinoma cell line) (10 $\mathrm{g} /$ well total protein) under nonreducing conditions using purified ascites derived monoclonal antibody $\mathrm{mAb} M-23.6 .1(10 \mu \mathrm{g} / \mathrm{ml})$ (lane 1) and the same antibody preabsorbed with peptide CD44 exon 7 (1-43aa) (lane 2). Lanes 3 and 4 are under the same conditions using spinner produced antibody (10 $\mu \mathrm{g} /$ ml) (lane 3) and preabsorbed with peptide CD44 exon 7 (1-43aa) (lane 4). 
Table 5 Immunocytochemical analysis of RT112, ZR75, MDA 4A4, and HT29 cell lines with crude ascites $(10 \mu \mathrm{g} / \mathrm{ml})$ and spinner produced antibodies $(10 \mu \mathrm{g} / \mathrm{ml})$

\begin{tabular}{llllllll}
\hline & \multicolumn{2}{l}{ Ascites } & & & \multicolumn{2}{l}{ Spinner } \\
\cline { 2 - 5 } \cline { 5 - 7 } Clone & RT112 & ZR75 & MDA & HT29 & & RT112 & MDA \\
\hline 23.6 .1 & ++++ & +++ & $+/-$ & - & +++ & - \\
23.46 .19 & ++ & ++ & - & - & + & - & - \\
23.57 .20 & +++ & + & - & - & ++ & - \\
\hline
\end{tabular}

- , No staining; + , weak membrane staining on $0-10 \%$ cells; ++ , weak membrane staining on $90 \%+$ of cells;,+++ moderate membrane staining on $90 \%+$ cells; ++++ , intense membrane staining on $90 \%+$ cells.
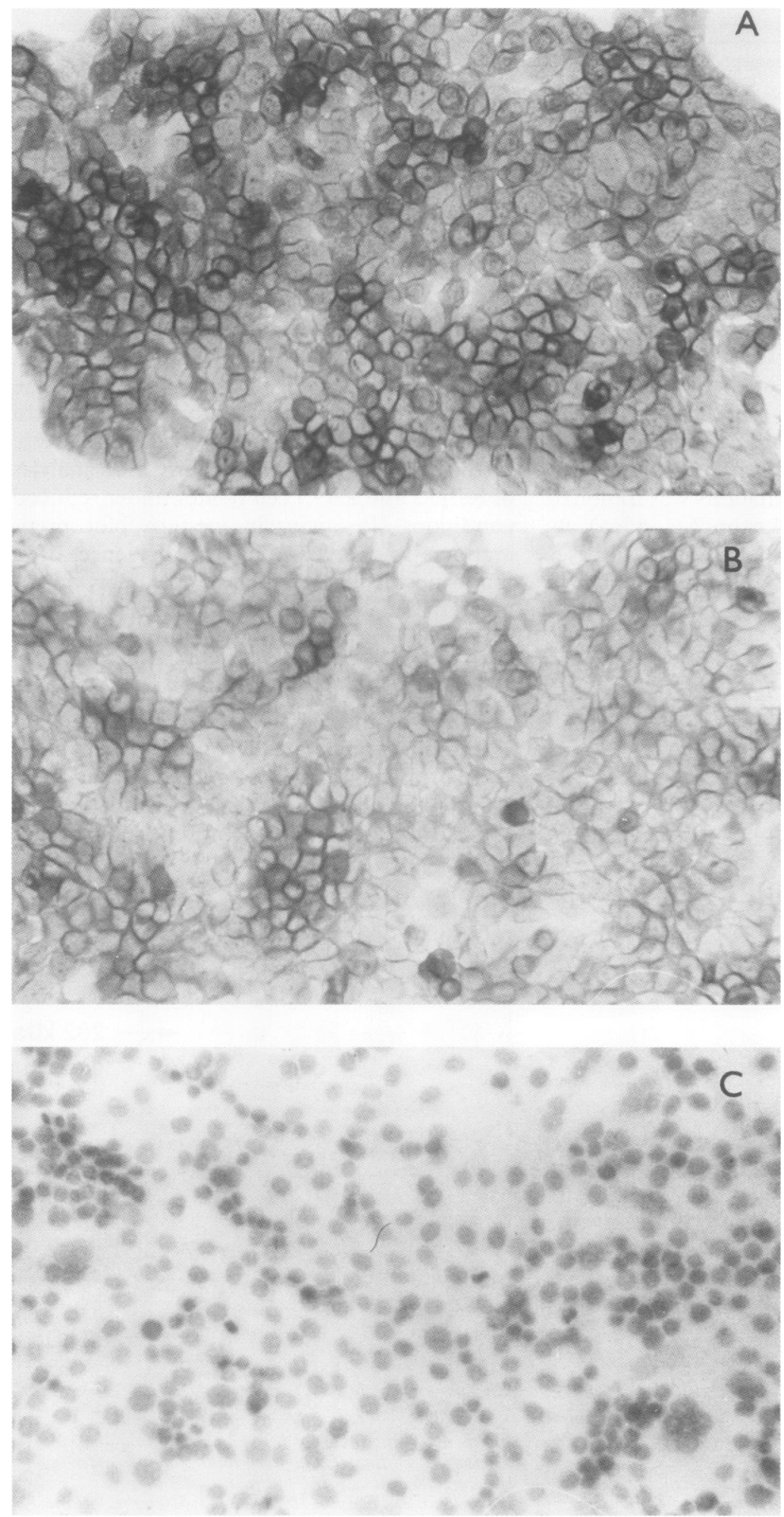

Figure 5 Immunocytochemical staining of RT112 human bladder carcinoa cell line with purified monoclonal antibody $M-23.6 .1(10 \mu \mathrm{g} / \mathrm{ml})$ obtained from ascites $(A)$ and spinner culture (B), showing strong membrane reactivity. The negative staining obtained with $M D A 4 A 4$ is shown in (C). Magnification $\times 590$. the intensity of this reaction varied significantly between clones.

Consequently, from these data, three CD44 exon 7 specific hybridomas were selected for further study on the basis that they showed marked positivity in both western blotting and immunocytochemistry on RT112 and ZR75-1 cell lines but not on HT29 or MDA 4A4. They were named $\mathrm{mAb}<\mathrm{CD} 44$ exon $7>\mathrm{M}-23.6 .1$ (IgG1, $\lambda$ ), mAb $<$ CD44 exon $7>\mathrm{M}-23.46 .19$ $(\operatorname{IgG1}, \kappa)$ and $\mathrm{mAb}<\mathrm{CD} 44$ exon $7>\mathrm{M}$ 23.57.20 (IgG1, $\lambda)$. The data in brackets refer to the immunoglobulin class.

\section{FACS analysis of monoclonal antibodies}

23.6.1, 23.46.19, and 23.57.20

FACS analysis of these three monoclonal antibodies shows positive binding with the CD44 exon 7 expressing cells RT112 (mAb 23.6.1. = $90 \% ; \mathrm{mAb} 23.49 .19=72 \% ; \mathrm{mAb} 23.57 .20=$ $86 \%$ ) and with ZR 75-1 (mAb 23.6.1.=97\%; $\mathrm{mAb} 23.49 .19 .=97 \% ; \mathrm{mAb} 23.57 .20 .=96 \%$ ) (fig 3). With the CD44 exon 7 negative MDA 4A4 cells, all three monoclonal antibodies showed only about $1 \%$ binding. Anti standard from $\mathrm{F}-10-44-2$ showed $100 \%$ binding with MDA 4A4 (fig 3). Unstimulated peripheral blood lymphocytes were found to be negative with all three monoclonal antibodies to products of exon 7 (data not shown).

\section{Characterisation and evaluation of} antibodies secreted by selected subclones Following bulk production of the antibodies secreted by these three selected clones, as described above, ascites and spinner culture fluids from each were characterised by western blotting and immunocytochemistry. In western blots performed under non-reducing conditions, antibodies obtained from all three hybridomas by either production method and standardised to a concentration of $10 \mu \mathrm{g} / \mathrm{ml}$ defined a single high molecular weight band corresponding to a size of just over $200 \mathrm{kDa}$ in both RT112 and ZR75-1. However, no bands were observed with MDA 4A4 and HT29.

Table 5 summarises the immunocytochemical data which showed differences both between clones and between production methods. In all cases staining was most intense on the cell membranes, but some cytoplasmic reactivity was seen.

As all three of these clones had previously been mapped to an epitope in the CD44 exon 


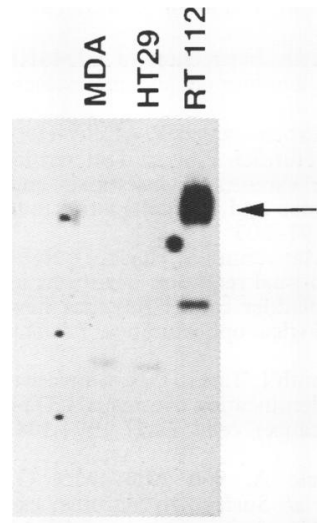

PAK 6127 (IS)

Figure 6 Western blot of RT112, MDA 4A4 and HT29 cell lines (10 $\mu \mathrm{g} / \mathrm{well}$ total protein) under reducing conditions using purified polyclonal antiserum $p A b$ S-6127. Arrow shows position of $220 k D a$ marker.
7 (19-33aa) region, we decided to purify only ascites and spinner supernatant of 23.6.1.

\section{CHARACTERISATION OF PROTEIN A PURIFIED}

mAb $<$ CD44 EXON 7>M-23.6.1

Western blotting with the purified monoclonal antibody identified a monospecific band of approximately $200 \mathrm{kDa}$ in RT 112 cell lysates, but not in those from control lines (HT29 and MDA 4A4) which are negative for exon 7 expression. Figure 4 shows a western blot on RT112 using pure ascites derived 23.6.1 (10 $\mathrm{g} / \mathrm{ml}$ ) (lane 1) and the specific inhibition of immunoreactivity by peptide CD44 exon 7 (19-33aa) (lane 2). Similar immunoreactivity was observed with spinner produced antibody $(10 \mu \mathrm{g} / \mathrm{ml}$ ) (lane 3) and diminished after inhibition with peptide CD44 exon 7 (19-33aa) (lane 4).

Immunocytochemical staining of RT112 (fig 5) with pure $23.6 .1(10 \mu \mathrm{g} / \mathrm{ml})$ obtained from ascites (A) and spinner (B) showed strong membrane reactivity. As with the crude preparations, more intense staining was observed with the ascites derived antibody. MDA 4A4 cells did not stain (C).

\section{CHARACTERISATION OF POLYCLONAL}

ANTI-CD44 EXON 7 ANTIBODIES

Several of the sera screened for immunoreactivity proved to be positive in both fusion protein and cell ELISAs. CD44 exon 7 peptide (1-43aa) immunosorbed antibodies showed several immunoreactive bands on Western blotting. The blot obtained with the most promising polyclonal antibody termed pAb $\mathrm{S}-6127$ is shown in fig 6 . With RT112 cell lysates, a major band of immunoreactivity was seen around $200 \mathrm{kDa}$, with a second minor band at between 140 and $160 \mathrm{kDa}$. With MDA 4A4 and HT29, a single minor band was seen at around 90-100 kDa. Immunocytochemistry on RT112 cells showed similar staining, both in terms of intensity and localisation, to that observed with the monoclonals, while apart from some weak background cytoplasmic staining, MDA 4A4 and HT29 were negative.

\section{Discussion}

This work has resulted in the isolation and molecular characterisation of a new monoclonal antibody with an internal image corresponding to an epitope encoded by exon 7 (v2) of the human CD44 gene. The immunoreactivity of the antibody with the products of exon 7 has been demonstrated in western blots performed on lysates of several human tumour cell lines, in which it reproducibly recognises a $220 \mathrm{kDa}$ mono-specific band and by peptide ELISA and cell ELISA techniques. We have evidence that the high molecular weight protein identified in western blots also contains the products of several other exons from the variably expressed region of the CD44 gene (data in preparation for publication). The specificity of this reactivity was further confirmed by competitive inhibition experiments using synthetic peptides and the fu- sion peptide employed for raising the antibodies in mice. The distribution of the epitope in the tumour cells studied is confirmed to be typically in the cell membrane, as would be expected for an integral transmembrane glycoprotein, but reactivity was also seen to a lesser extent in the cell cytoplasm. This is interpreted to be the epitope on its way to insertion in the membrane, but may also represent excess abnormal protein accumulating in the cytoplasm of tumour cells, with disordered processing of this complex molecule.

Further studies using this new antibody on human tumour cell lines and on frozen and paraffin wax embedded sections of normal and tumour tissues have confirmed that the increased transcripts from the v2 exon previously seen in several human tumour tissues and in tumour cell lines (data to be published separately) are translated into proteins. This immunocytochemical and immunohistochemical work has been conducted on cells and tissues from many patients with carcinoma of the urinary bladder, colon, and breast. Weak cross reactivity with mucin droplets in colonic epithelial cells has been identified but this is not of any diagnostic consequence.

We have also described the production of the polyclonal antiserum (pAb S-6127) to CD44 exon 7. It appears to be useful for western blotting and immunocytochemistry. Furthermore, pAb S-6127 is currently undergoing evaluation in a sandwich-ELISA system, where the use of purified polyvalent antibodies may be beneficial.

Several previous studies, ${ }^{11-16}$ from this and other laboratories, have confirmed abnormal transcription and splicing of the CD44 gene in tumour cells relative to their normal counterparts, and the presence of abnormal large CD44 protein isoforms has recently been shown ${ }^{25}$ in exfoliated cancer cells in the urine of patients with bladder cancer. The reproducibility and specificity of such differences between samples from the bladder cancer patients and from unaffected control subjects suggests that abnormal patterns of CD44 expression may be a useful marker for the early detection of some types of malignancy. The new antibodies described in this paper may be a helpful reagent in the analysis of CD44 gene expression in normal and neoplastic cells. It may also be useful in the search for new sensitive and specific tests for cancer cells in clinical specimens.

In this context, it is relevant to mention that the presence of exon 7 (v2) of this gene was first suspected from RT-PCR observations on the human tumour specimens ${ }^{11}$ in which a PCR product $(1650 \mathrm{bp})$, which was too large for the then known structure of the CD44 locus, was detected in all tumour specimens. This does not mean that the expression of this exon is the cause of the neoplasm, but it does indicate that large isoforms containing products of all coding regions of the CD44 gene are characteristically overexpressed in cancer cells. It is possible that unbalanced expression of one or of a group of exons is an important aetiological factor in, or a specific marker of, neoplasia. 
The new antibody will be a useful tool for the further analysis of these abnormal CD44 isoforms and their clinical implications. We wish to acknowledge with gratitude the valuable help given
by Dr E Hoess, Dr W Rollinger, Dr S Goodison, Dr H Bodenmuller, Dr M Kaufmann, Mrs L Summerville, and Miss H Mellor. We also thank Dr J E Price for the gift of the MDA MB435 cell line.

1 MacKay CR, Terpe H-J, Stauder R, Marston WL, Stark $\mathrm{H}$, Gunthert U. Expression and modulation of CD44 variant isoforms in humans. $\mathcal{F}$ Cell Biol 1994;124:71-82. 2 Screaton GR, Bell MV, Jackson DG, Cornelis, Gerth U, Bell JI. Genomic structure of DNA encoding the lymphocyte homing receptor CD44 reveals at least 12 alternatively spliced exons. Proc Natl Acad Sci USA 1992;89:12160-4.

3 Jalkanen S, Bargatze RF, del los Toyos J, Butcher EC. Lymphocyte recognition of high endothelium: antibodie to distinctly epitopes of an $85-95 \mathrm{kD}$ glycoprotein antigen differentially inhibit lymphocyte binding to lymph node, 105:983-90.

4 Jalkanen S, Jalkanen M, Bargatze R, Tammi M, Butcher EC. Biochemical properties of glycoproteins involved in lymphocyte recognition of high venules in man. F Immunol lymphocyte recognition

5 Underhill CB, Green SJ, Comoglio PM. Tarone G. The hyaluronate receptor is identical to a glycoprotein of $\mathrm{M}$ 85000 (gp85) as shown by a monoclonal antibody that interferes with binding activity. F Biol Chem 1987;262 $13142-5$

6 Aruffo A, Stamenkovic I, Melnick M, Underhill CB, Seed B. CD44 is the principle cell surface receptor for hyaluronate. Cell 1990;61:1303-13.

7 Carter WG, Wayner EA. Characterisation of the class III collagen receptor, a phosphorylated, transmembrane glycoprotein expressed in nucleated human cells. $f \mathrm{Biol}$ Chem 1989;263:4193-201.

8 Gallatin WM, Wayner EA, Hoffman PA, St John T, Butcher EC, Carter WG. Structural homology between lymphoEC, Carter WG. Structural homology between lympho-
cyte receptors for high endothelium and class III excyte receptors for high endothelium and class III ex-
tracellular matrix receptor. Proc Natl Acad Sci USA 1989; 86:4654-8

9 Stamenkovic I, Amiot M, Pesando JM, Seed B. A lymphocyte molecule implicated in lymph node homing is member of the cartilage link protein family. Cell 1989;56: $1057-62$.

10 Gunthert U, Hofmann M, Rudy W, Reber S, Zoller M, Haussmann I, et al. A new variant of glycoprotein CD44 confers metastatic potential to rat carcinoma cells. Cell confers metastatic

11 Matsumura Y, Tarin D. Significance of CD44 gene products for cancer diagnosis and disease evaluation. Lancet 1992; 340:1053-8

12 Tanabe KK, Ellis LM, Saya H. Expression of CD44R1 adhesion molecule in colon carcinomas and metastases. Lancet 1993;341:725-6.

13 Heider K-H, Dammrich J, Skroch-Azngel P, Muller-Hermelink H-K, Vollmers HP, Herrlich P, et al. Differential melink H-K, Vollmers HP, Herrlich P, et al. Differential diffuse-type gastric carcinomas and normal gastric mudiffuse-type gastric carcinomas and

14 Matsumura Y, Sugiyama M, Matsumura S, Hayle AJ, Robinson P, Smith JC, et al. Unusual retention of introns in CD44 gene transcripts in bladder cancer provides new diagnostic and clinical oncological opportunities. $\mathcal{F}$ Pathol (in press).

15 Matsumura Y, Hanbury D, Smith J, Tarin D. Non-invasive detection of malignancy by identification of unusual CD44 gene activity in exfoliated cancer cells. BMF 1994;308 gene activi

16 Dall $P$, Heider K-H, Hekele A, von Minchwitz G Kauffmann M, Ponta $\mathrm{H}$, et al. Surface glycoprotein expression and messenger RNA-splicing analysis of CD44 in uterine cervical cancer and normal cervical epithelium. Cancer Res 1994;54:4754-6.

17 Wielenga VJM, Heider K-H, Offerhaus GJA, Adolf GR van den Berg FM, Ponta $\mathrm{H}$, et al. Expression of variant CD44 proteins in human colorectal cancer is related to tumour progression. Cancer Res 1993;53:4754-6.

18 Kaufmann M, Heider K-H, Sinn H-P, von Minckwitz G, Ponta H, Herrlich P. CD44 variant exon epitopes in primary breast cancer and length of survival. Lancet 1995; primary brea

19 Guyader M, Emerman M, Sonigo P, Clavel F, Montagnier $\mathrm{L}$, Alizon M. Genome organisation and transactivation of the human immunodeficiency virus type 2. Nature 1987 326:662-9.

20 Stueber D, Matile H, Garotta G. System for high level production in Escherichia coli and rapid application to epitope mapping, preparation of antibodies and structurefunction analysis. Immunol Methods 1990;4:121-52.

21 Mullis KB, Faloona FA. Specific synthesis of DNA in vitro via a polymerase-catalyzed chain reaction. Methods vitro via a polymerase-catalyz

22 Murray NE, Brammar WJ, Murray K. Lambdoid phages that simplify the recovery of in vitro recombinants. Mol Gen Genet 1977; 150:53-61.

23 Hochuli E, Doebeli H, Schacher A. New metal chelate adsorbent selective for proteins and peptides containing neighbouring histidine residues. $f$ Chromatogr 1987;411: $177-84$.

24 Kohler G, Milstein C. Continuous cultures of fused cells screting antibody of pre-defined specificity. Nature 1975; 256:495-97.

25 Sugiyama M, Woodman A, Sugino T, Crowley S, Ho K, Smith J, et al. Non-invasive detection of bladder cancer by identification of abnormal CD44 proteins in exfoliated cells in urine. f Clin Pathol: Mol Pathol 1995;48:M142-7. 